\title{
Electromagnetic Modelling and Detection of Buried Stator Core Faults
}

DOI:

10.1049/iet-epa.2016.0470

Document Version

Accepted author manuscript

Link to publication record in Manchester Research Explorer

\section{Citation for published version (APA):}

Bertenshaw, D. R., Ho, C. W., Smith, S., Sasic, M., \& Chan, T. (2017). Electromagnetic Modelling and Detection of Buried Stator Core Faults. IET Electric Power Applications, 11(2), 187-196. https://doi.org/10.1049/ietepa.2016.0470

\section{Published in:}

IET Electric Power Applications

\section{Citing this paper}

Please note that where the full-text provided on Manchester Research Explorer is the Author Accepted Manuscript or Proof version this may differ from the final Published version. If citing, it is advised that you check and use the publisher's definitive version.

\section{General rights}

Copyright and moral rights for the publications made accessible in the Research Explorer are retained by the authors and/or other copyright owners and it is a condition of accessing publications that users recognise and abide by the legal requirements associated with these rights.

\section{Takedown policy}

If you believe that this document breaches copyright please refer to the University of Manchester's Takedown Procedures [http://man.ac.uk/04Y6Bo] or contact uml.scholarlycommunications@manchester.ac.uk providing relevant details, so we can investigate your claim.

\section{OPEN ACCESS}




\title{
Electromagnetic Modelling and Detection of Buried Stator Core Faults
}

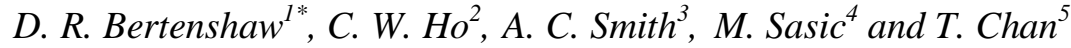 \\ ${ }^{1}$ ENELEC LTD, Lightwater, GU18 5XX, UK (corresponding author) \\ 2 Republic Polytechnic, School of Engineering. Singapore 738964 \\ ${ }^{3}$ School of Electrical and Electronic Engineering, University of Manchester, M13 9PL, UK \\ ${ }^{4}$ Iris Power LP, Toronto, L4V 1T2, Canada \\ ${ }_{\text {A }}^{5}$ Aurecon Australia Pty Ltd, Victoria 3008, Australia \\ drb@enelec.org.uk
}

\begin{abstract}
Interlamination insulation faults in the stator cores of large electrical machines can damage both winding insulation and stator core, thus confidence in electromagnetic test results is important. They may be validated by FE methods, however the 3D models required for short faults are computationally challenged by laminated structures, requiring approximations. A homogenised 3D FE model was used to model faults buried in the teeth and yoke of the core, with a new experimental methodology developed to calibrate fault currents. Limitations were identified in modelling just a core section due to images and the constraint of axial packet air gaps on fault flux dispersion. A system of transverse 2D FE models of the principal fault flux paths in the core were constructed to estimate the differential impact on fault signals by the air gap presence and applied to the 3D FE model. Together with corrections for images this gave close predictions of experimental results, supporting the validity of the model. The verified electromagnetic test results now permit assessment of the threat that a detected buried fault presents.
\end{abstract}

\section{Introduction}

In large electrical machines such as utility generators, if the insulation on a number of stator core laminations becomes shorted together due to damage or aging [1], the consequent induced eddy currents can cause local heating to occur at the damage. This, can affect the life expectancy of nearby conductor insulation [2], and in extreme cases lead to melting of the stator steel [3]. Effective stator core testing is only possible at service intervals [4], and thus relies on the ability of the test to detect a developing stator core fault (SCF) before it becomes dangerous. 
Testing initially used a high flux test to detect faults by their local heating (typically $>10^{\circ} \mathrm{C}$ ) [5] at full flux. The high energies and hazards of this test encouraged the development of an alternate electromagnetic test in 1979, the EL CID system [6], operating at typically $4 \%$ of service flux. This is now in common use worldwide [7].

In this test, fault currents induced in damaged areas are measured by sensing their magnetic potential difference (mpd) across the bore's slot teeth edges using a narrow air-cored coil known as a Chattock potentiometer. Any fault current is detected as that mpd in quadrature to the excitation field, indicated as a 'Quad' current [8], with the recommendation that signals above $100 \mathrm{~mA}$ 'be investigated further' [9]. The two tests have been shown to correlate in practice at $\sim 9{ }^{\circ} \mathrm{C} / 100 \mathrm{~mA}[10]$, and to similarly correlate to common alternate electromagnetic systems e.g. DIRIS [11].

Stator core faults can occur from a variety of sources such as incorrect manufacture, overheating, vibration, core looseness, foreign body impact and many other mechanisms [1]. While the majority of reported core faults occur on the core surface [10], sources such as vibration and interlamination insulation aging deteriorations can act at any point in the core body causing buried faults. The relative paucity of detected buried faults may however be exacerbated by their lower detectability, a problem since they can be very destructive with the ability to rapidly destroy a generator [12].

Their detectability is reduced compared to surface faults since the buried fault's surrounding steel causes the surface mpd detected by the Chattock sensor to be attenuated, an attenuation problem even greater for the high flux test [7]. Consequently positive signals from both electromagnetic and high flux tests are still recommended before major stator repair/replacement [7, 13].

\section{FE Modelling of Stator Core Faults}

The Chattock only senses the resultant mpd in that region and does not provide any information regarding the distribution of the current or interlamination insulation damage. Studies using 2D Finite Element (2D FE) modelling of a SCF [14-16] have predicted the signals seen and their amplitudes for long faults, while analytic 3D work has also shown the current distribution in short faults [17]. However the typical short fault length $(5 \sim 50 \mathrm{~mm})$ causes 2D FE models to always over-estimate their detected fault current.

More accurate analysis requires a 3D FE model which adequately reflects the lamination structure, but remains a challenging problem to develop realistic models that are computable. Some research has used homogenisation techniques to simplify the modelling of stator lamination stacks [18, 19], however the test results from a modelled SCF [20] differed significantly. An alternate approach used special elements to explicitly model the interlamination boundaries [21], but the computational burden, 
even without axial conductivity, still required the Japanese 'Earth Simulator' supercomputer to model a small machine segment at lamination level [22].

Buried faults have been very little studied due to their difficulty. The few published studies have nearly all been 2D FE [15, 23, 24]. Sutton [25] completed a 3D analytic study of surface faults, but assumed infinite fault length (i.e. 2D) when extending the study to buried faults. The only 3D FE study of buried faults was Henneron et al [26] who studied the detection of a buried fault of just two laminations connected, obtaining a very unlikely detection sensitivity of $60 \%$. Further no reliable experimental work is reported on buried faults, the sole studies [27, 28] produced inconclusive or no results and had no means of calibrating the faults. In consequence there is no dependable electromagnetic means of quantifying the threat from a detected buried core fault.

Recognising these limitations, a 3D FE model of a stator core section with surface and buried faults was developed by Ho et al. [29] using a homogenised model of the laminations. Regional axial permeability was adjusted to model the stacking factor with axial conductivity permitted in the SCF region. Experimental verification of the surface faults successfully matched the modelled results within $8 \%$ for fault lengths from 10-40 mm. However the buried faults within the core teeth and yoke were not analysed or experimentally verified, and are the subject of this paper.

\section{3D FE Stator Core Model}

The 3D FE modelled stator core in [29] is a $60^{\circ}$ segment with the fault locations indicated in Figure 1(b). The buried faults Fault_4-6 were modelled with calibrated fault resistivities for lengths of 10/20/40 mm, with simulated Chattock test signals recorded. Fault_7 was too close to the core rear to generate any detectable signal, so was omitted from the study.

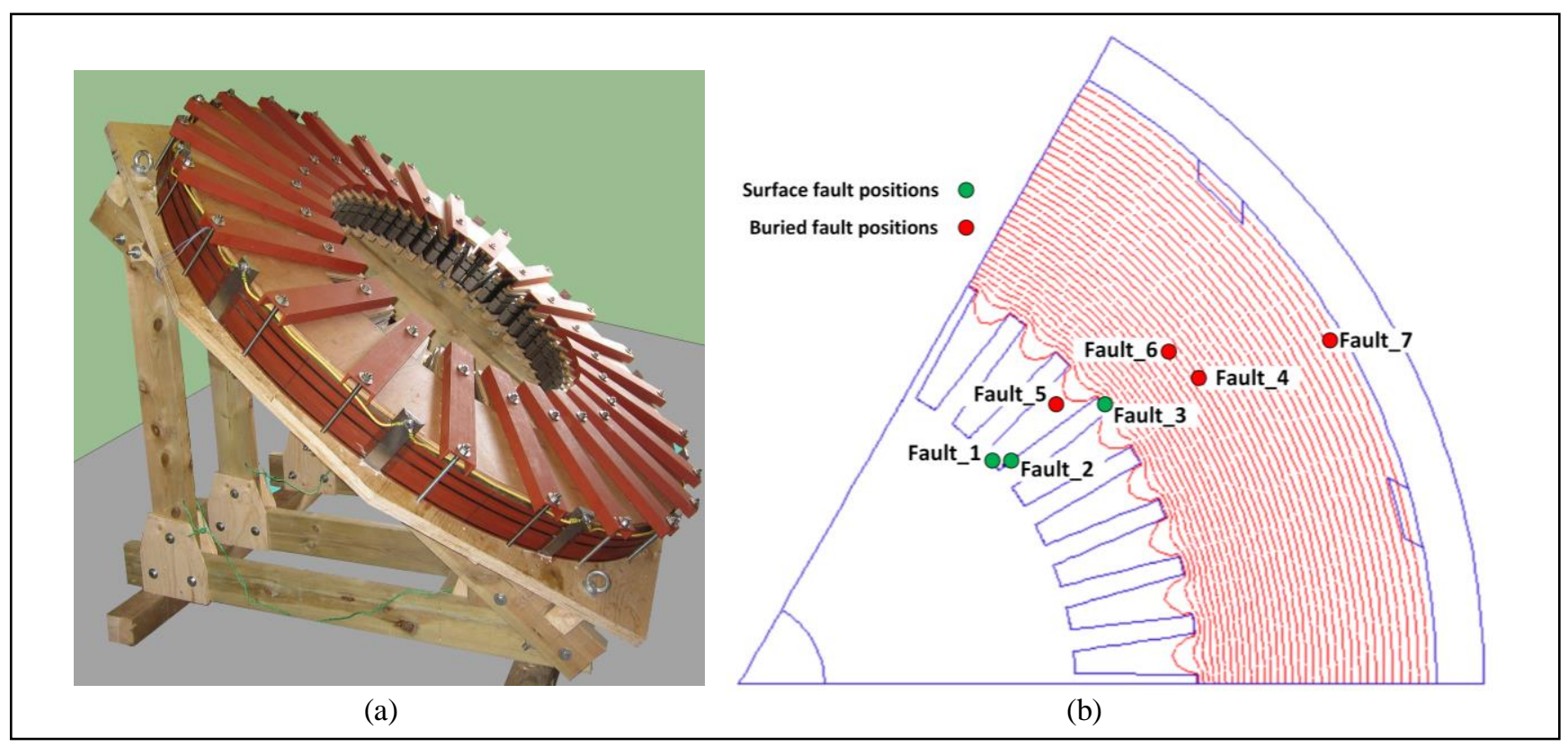

Figure 1. (a) Experimental Test stator core, (b) Fault positions 
It was shown in [29] that the use of an axially limited model section results in interfering fault images, and the model's axial extent had been considerably increased to eliminate these. However the 3D FE core model segment was only 8 slots out of 48, which resulted in another 5 fault images repeating circumferentially around the missing core. This causes an effect of Quad Recovery [30], where each image's circulating fault flux around the core causes an opposing mpd at the actual fault. Thus assuming uniform Quad Recovery, circumferential image correction was achieved by scaling the 3D FE model Quad signal results by $8 / 7 \times 47 / 48=111.9 \%$.

\section{Experimental Configuration}

Experimental validation was completed on a 48 slot Test core shown in Figure 1(a) comparable (2032 mm dia.) but perforce 14\% larger than the modelled experimental core [29] with a similar overall height, central $50 \mathrm{~mm}$ packet and $8 \mathrm{~mm}$ axial vent spacers. It was proved as intrinsically faultfree by both EL CID and high flux tests, with all laminations contacting keybars. In a short core, nonlinear permeability can cause interfering harmonics from the excitation current [31] to appear in the induced flux waveform. These were reduced to $0.12 \%$ THD by flux feedback compensation of the excitation source.

Buried test Fault_4 and Fault_6 positions were maintained the same absolute depth below slot base as the 3D FE model, and Fault_5 the same proportion of tooth depth. The increased size of the experimental core thus required scaling of test results due to the increased yoke depth increasing the test axial voltage gradient driving the fault current, plus for Fault_4 and Fault_6 small increases in proportion of core test flux coupled into the fault circuit and increased angle subtended to the teeth roots, across which the Chattock measures the developed mpd.

To validate the measurement competence the 3D FE modelled surface fault positions of Fault_1-3 were re-measured on the Test core. The scaled Test core mean error compared to original results in [29] was found to be $-5.4 \%$. Since this difference was within the experimental error and uncertainty margin, no further compensation to accommodate this difference was made in subsequent measurements.

The buried fault sites were prepared inside $9 \mathrm{~mm}$ dia. holes bored axially through the core in the positions Fault_4-6 and electro-etched fault-free. Calibrated length $0.45 \mathrm{~mm}$ dia. NiCr resistance wires to simulate each fault in turn were supported in a resilient mount on an insulated mandrel, expanded after insertion into the hole with a $2 \mathrm{~mm}$ thick stainless steel blade to pressurise the contact between the wire and the hole's prepared lamination edges, shown in Figure 2. All faults were applied centrally in the $50 \mathrm{~mm}$ packet. 


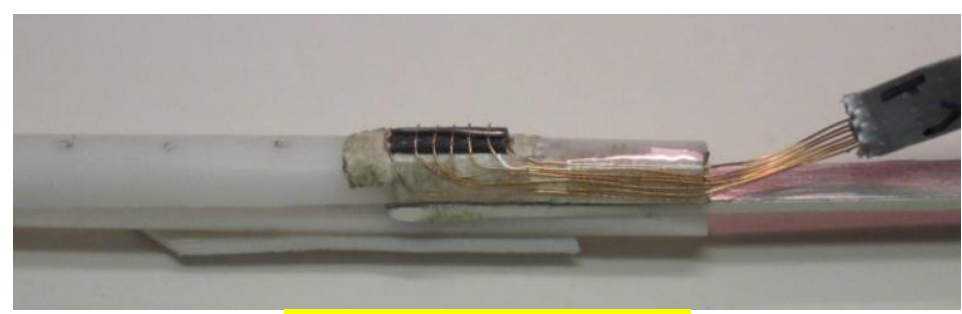

Figure 2. Buried fault test jig

To determine the disturbance of the hole on the electromagnetic field, a FEMM [32] 2D FE model was developed of the Test core with the $9 \mathrm{~mm}$ hole towards the bore of the fault positions. This orientation was chosen to minimise the hole's impact on fault current distribution which would be more complex to model. Since the hole is bored the full core axial length, it is validly modelled in 2D. The model predicted small increases in detected mpd shown in Table 1, which were compensated for in the results.

\begin{tabular}{l|r|r|r}
\hline Fault & $\begin{array}{c}\text { Depth from slot base in } \\
\text { 3D FE model }\end{array}$ & $\begin{array}{c}\text { Depth from slot base in } \\
\text { Test core }\end{array}$ & $\begin{array}{c}\text { FE increase from } \\
\text { 9 mm hole }\end{array}$ \\
\hline Fault_4 & $116 \mathrm{~mm}(38 \%)$ & $116 \mathrm{~mm}(34 \%)$ & $+4.2 \%$ \\
\hline Fault_5 & $103 \mathrm{~mm}(67 \%)$ & $125 \mathrm{~mm}(67 \%)$ & $+0.4 \%$ \\
\hline Fault_6 & $107 \mathrm{~mm}(35 \%)$ & $107 \mathrm{~mm}(31 \%)$ & $+4.6 \%$ \\
\hline \multicolumn{3}{r}{ Table 1. Buried fault positions in $3 D$ FE model and Test core with effect of hole }
\end{tabular}

\section{FE Validation at Equal Fault Flux and Fault Current}

The most direct comparison is to compare scaled test results such that the coupled total flux in each fault is equal to the 3D FE flux, as achieved in the scaled Test core results. The example for Fault_6 is plotted in Figure 3 below for 10, 20 and $40 \mathrm{~mm}$ long faults, with the reference position within the $50 \mathrm{~mm}$ Test core packet shown symbolically. The equal flux scaled results for the three fault positions are given in Table 4. These show a close mean correlation, however the deviation is quite large. 
This article has been accepted for publication in a future issue of this journal, but has not been fully edited. Content may change prior to final publication in an issue of RejoirsiantRedv for paper please use the doi provided on the Digital Library page.

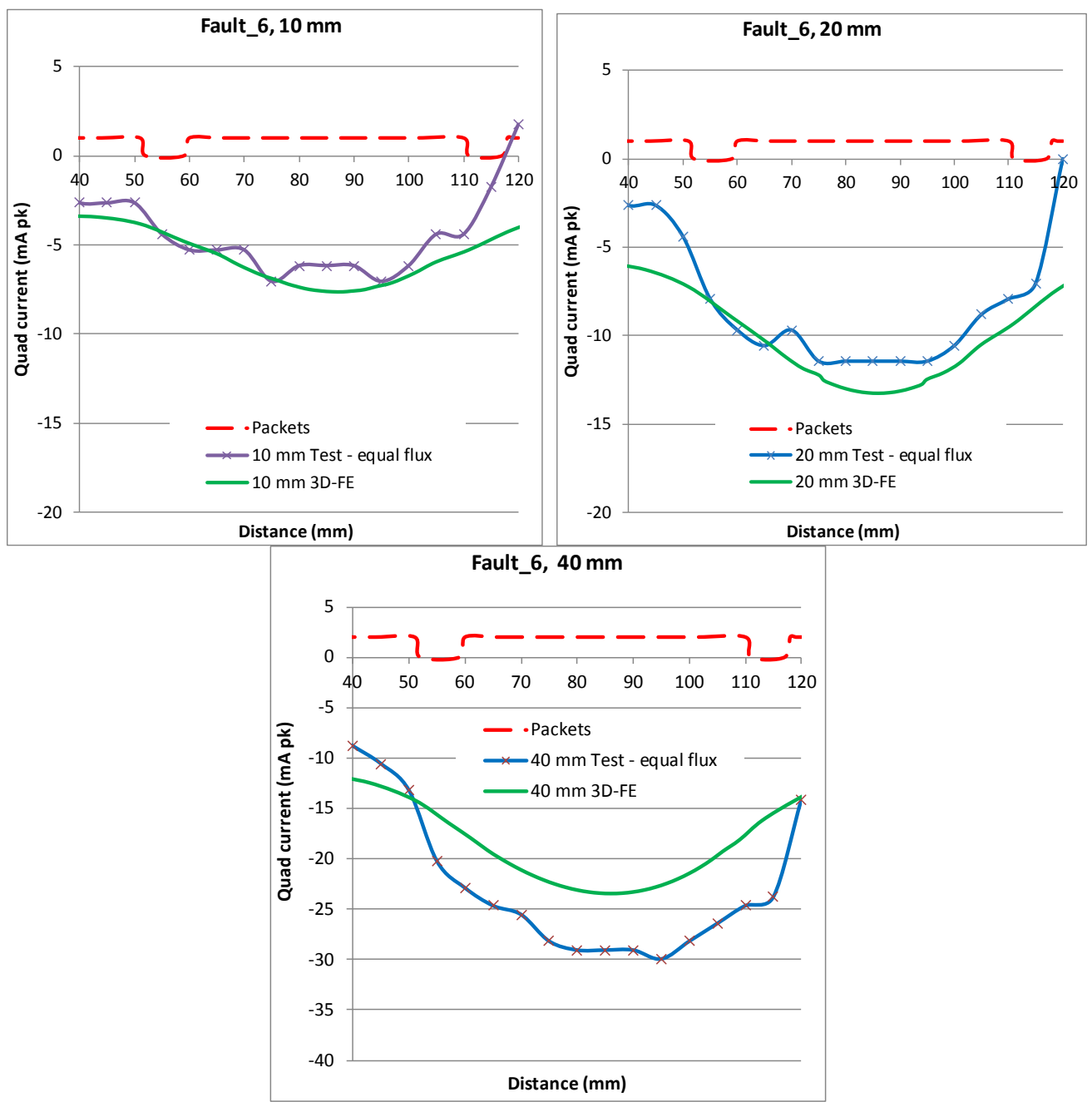

Figure 3. Fault_6 measured and 3D FE buried fault Quad signals scaled to equal flux

The 3D FE modelled fault currents shown in Figure 4(a\&c) were totally uniform and 95-104\% of 2D theoretical value, whereas 3D analytic models of short fault currents [17] have demonstrated significant non-uniformity with central bias. The actual fault currents were determined by voltage sense wires contacting the $\mathrm{NiCr}$ fault wire as shown in Figure 2, calculated from the measured differential voltages and wire resistivity assuming effective lamination contact lengths of $90 \%$ of the fault wire lengths. These were scaled to equal the 3D FE model flux (hence equal axial voltage gradient).

Sample results in Figure 4(b\&d) show that the real faults do not achieve the expected currents from the FE model, with even more central bias due to the additional lamination contact resistances. In order to solely compare the 3D FE modelling of the electromagnetic fault detection with test results, the measured Quad signals were linearly scaled such that the mean fault current over each fault matched the 3D FE values. The revised results are shown in Table 4. 
(a)
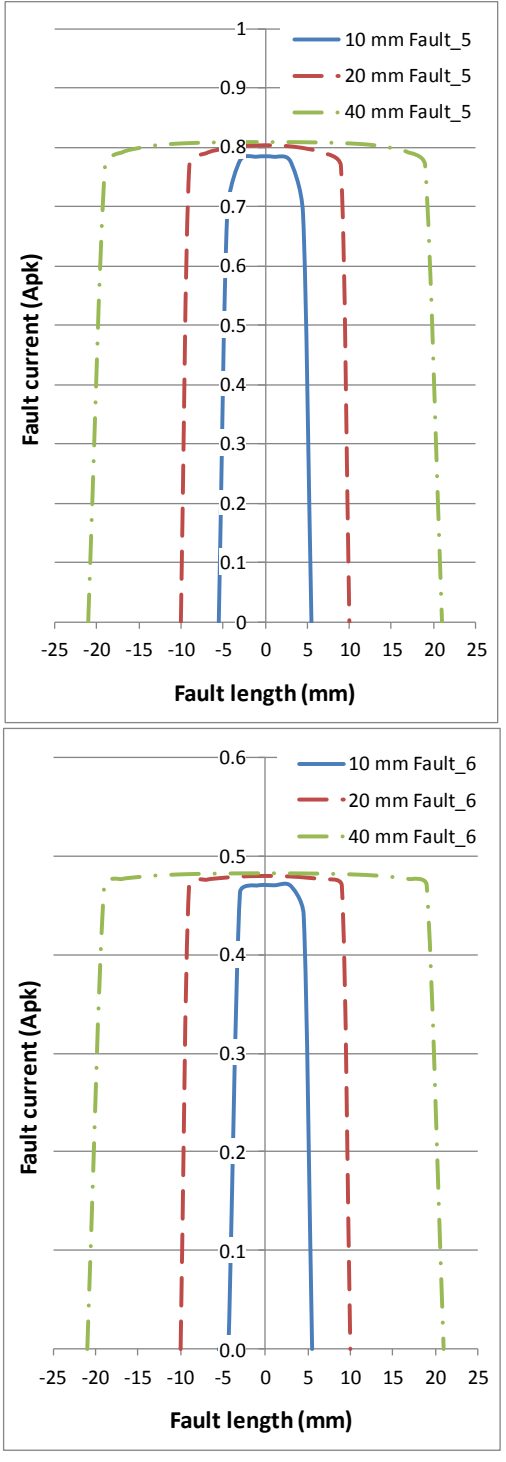

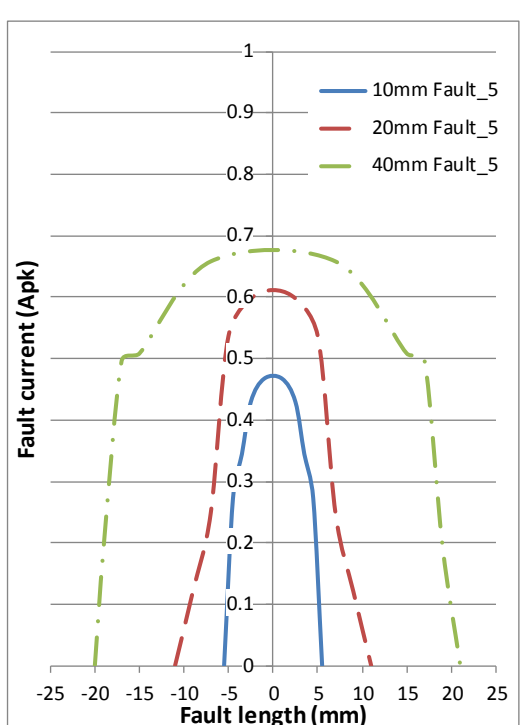

(b)

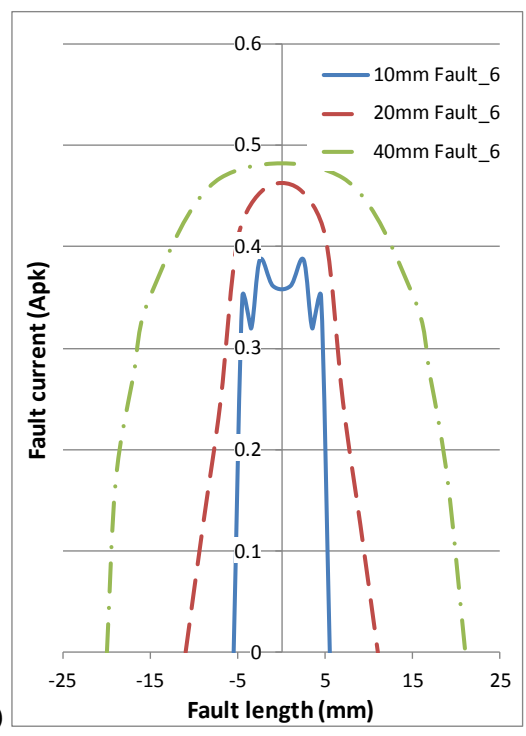

Figure 4. Fault_5-6 current distributions, $(a \& c) 3 D$ FE model, $(b \& d)$ Test core measured

The poor modelling effectiveness for faults $>10 \mathrm{~mm}$ is most likely caused by the 3D FE model having a long $(620 \mathrm{~mm})$ and axially continuous core devoid of any packet gaps. By contrast the Test core has $8 \mathrm{~mm}$ wide packet axial air gaps either side of the $50 \mathrm{~mm}$ long packet carrying the fault, a very conventional construction. The flux from the longer experimental faults is thus potentially constrained by the packet air gap barriers, amplifying the resultant magnetic field strength. This showed there was a need to determine and compensate for the effect the air gaps could cause.

\section{Model Compensation for Air Gaps}

\subsection{The Impact of Axial Packet Air Gaps}

Fault currents flowing in the core body induce a flux that circulates both around the fault and around the core body, shown in Figure 5. The flux that circulates around the core will diverge axially away from the fault plane around the core body, reducing the effective reluctance of this region. This 
will in turn reduce the flux density and hence magnetic field strength developed across the slot by the fault. Further the flux that flows around the short fault, since it will be shown to be primarily induced by the fault currents returning in the laminations, may also diverge axially in the core in the region of the tooth roots, thus reducing the magnetic field strength developed there. Finally the Chattock detects the magnetic potentials at the tooth tips, not the roots. Thus the axial attenuation of magnetic potential to the tooth tip from the root will be controlled by the difference between radial reluctance of the tooth and the reluctance of the air in the slot between the teeth.

It can be seen that all these effects are affected by the presence or absence of packet air gaps, since these substantially change the regional axial permeability of the core. As discussed in section 2, a whole core 3D FE model to lamination level remains impractical. In consequence an approximate system of three 2D FE FEMM models was developed of the three regions identified above. This approach is comparable to [30], and since the fault flux in these models is dominant in the model plane, they should be fairly representative of the impact of air gaps. The purpose of these models is not to directly predict the developed fault signal, but to estimate the extent to which presence of packet air gaps affects the signal. The bulk parameters are set to approximate any 3D asymmetry [33], with the permeability of the packet air gaps varied in each model so as to obtain a metric for their differential effect. These are used to provide an estimate of the differential change in detected fault signal as a result of presence of the packet airgaps in the three regions, which can be applied to produce the corrected 3D FE fault signal.

\subsection{D FE Model of Whole Core}

Initially a conventional axial stator 2D FE model was constructed, consisting of the whole core to avoid the complexity of image artefacts, shown in Figure 5 with Fault_6 injected at 1 A current. The inside and outside is air, with the steel having the same relative permeability of 3000 as the 3D FE models. Two regions of the whole core are defined for analysis; the four slots nearest the fault where the fault flux circulates is termed the 'fault region', the rest of the core yoke containing the remaining 44 slots is the 'core body'. It can be seen that that the great majority of the induced fault flux flows around the fault, with in this case only $13 \%$ circulating instead around the core yoke. The Chattock locus detecting the fault signal mpd is illustrated across the tooth tips. 


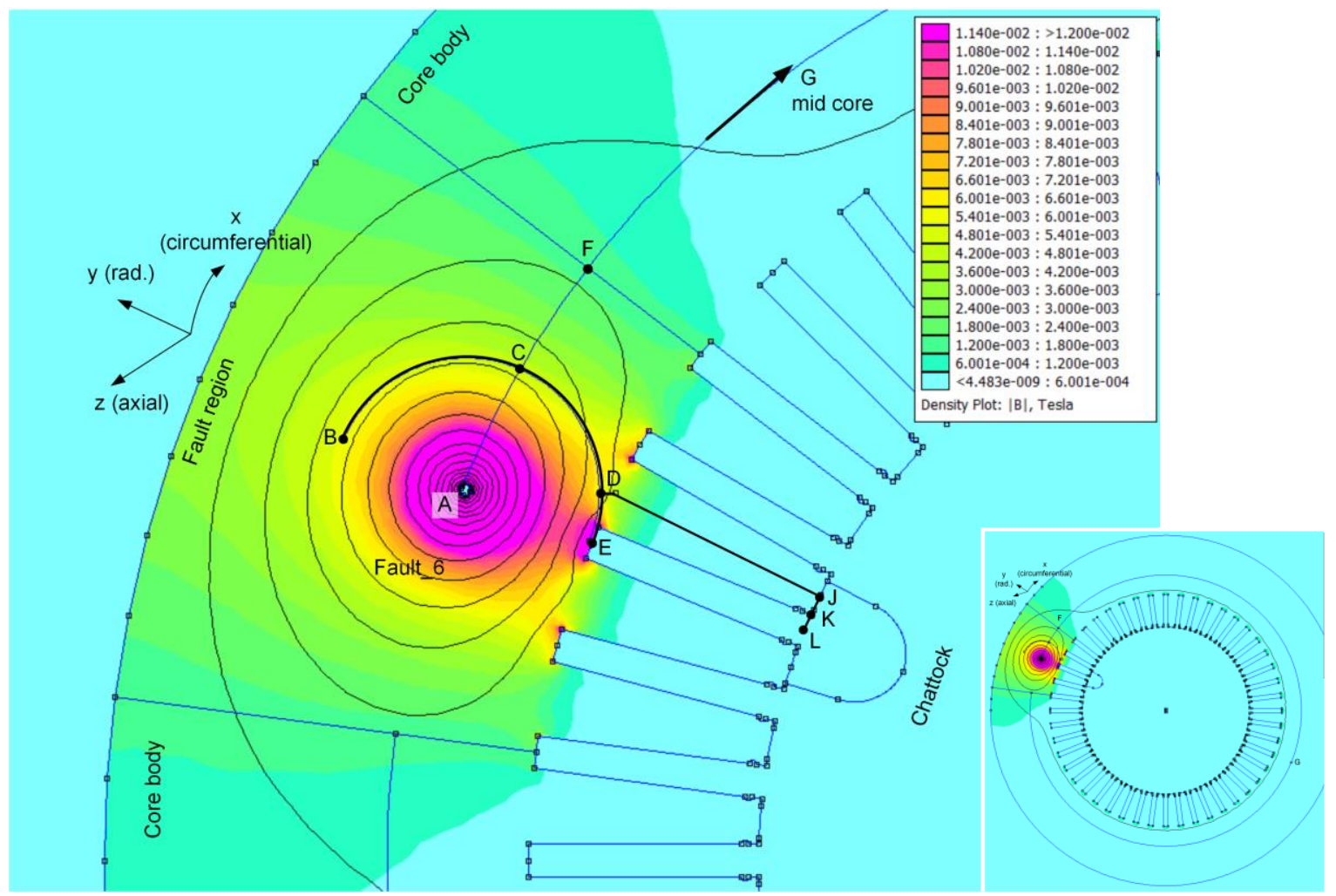

Figure 5. Test core Fault_6 axial 2D FE model (whole core inset)

The magnetic field detected by the Chattock from a short constant axial fault current in the Test core can be computed for a homogeneous medium from Biot-Savart (the other fault circuit currents cancel each other or are too distant) for a homogeneous medium. The resulting mpd developed across the slot root pitch is shown in Table 2 to be a great under-prediction of that measured, due to the inhomogeneous nature of the laminated core. In consequence the large majority of the mpd measured from these buried faults must be developed by the flux created by the fault's radial currents in the laminations, circulating around the fault and the core body. Table 2 also illustrates the great overprediction from 2D FE models of short buried fault signals.

\begin{tabular}{l|r|r|r}
\hline Fault_6 length (1 A fault current) & \multicolumn{1}{|c|}{$\mathbf{1 0} \mathbf{~ m m}$} & $\mathbf{2 0} \mathbf{~ m m}$ & \multicolumn{1}{|c|}{$\mathbf{~} \mathbf{~ m m}$} \\
\hline 2D FE modelled mpd across tooth-tips & $196 \mathrm{~mA}$ & $196 \mathrm{~mA}$ & $196 \mathrm{~mA}$ \\
\hline Measured mpd across tooth-tips (scaled to 1 A) & $22.7 \mathrm{~mA}$ & $39.5 \mathrm{~mA}$ & $85.5 \mathrm{~mA}$ \\
\hline Biot-Savart axial current slot root pitch mpd & $6.1 \mathrm{~mA}$ & $12.2 \mathrm{~mA}$ & $24.0 \mathrm{~mA}$ \\
\hline Biot-Savart axial current mpd proportion & $27 \%$ & $31 \%$ & $28 \%$ \\
\hline
\end{tabular}

Table 2. Biot-Savart prediction of detected Fault_6 mpd on Test core at fault centre

\subsection{Core Body Transverse 2D FE Model of Flux Axial Dispersion}

To model the change in the proportion of flux that flows around the axial fault current, due to changes in the reluctance of the core body caused by the presence of packet air gaps, a transverse (cutting the core axially) magnetostatic 2D FE model for Fault_6 was developed around half the core 
circumference. The flux is induced by a radial current source, exploiting the discovery above that the majority of the fault's flux is induced by radial current flow. The model follows central packet locus ACFG in Figure 5 and Figure 6(a) (yellow section), with axial and circumferential mirror symmetry. The visualisation in Figure 6 has the Figure 5 axial flux lines image superimposed for reference. Permeability was set at 25 in the z-axis, to reflect the stacking factor of 0.96 . The fault current is axially visualised in red in Figure 6(a) and set at 1 A radially in Figure 6(b) at lhs of the 2D FE model.

(b)
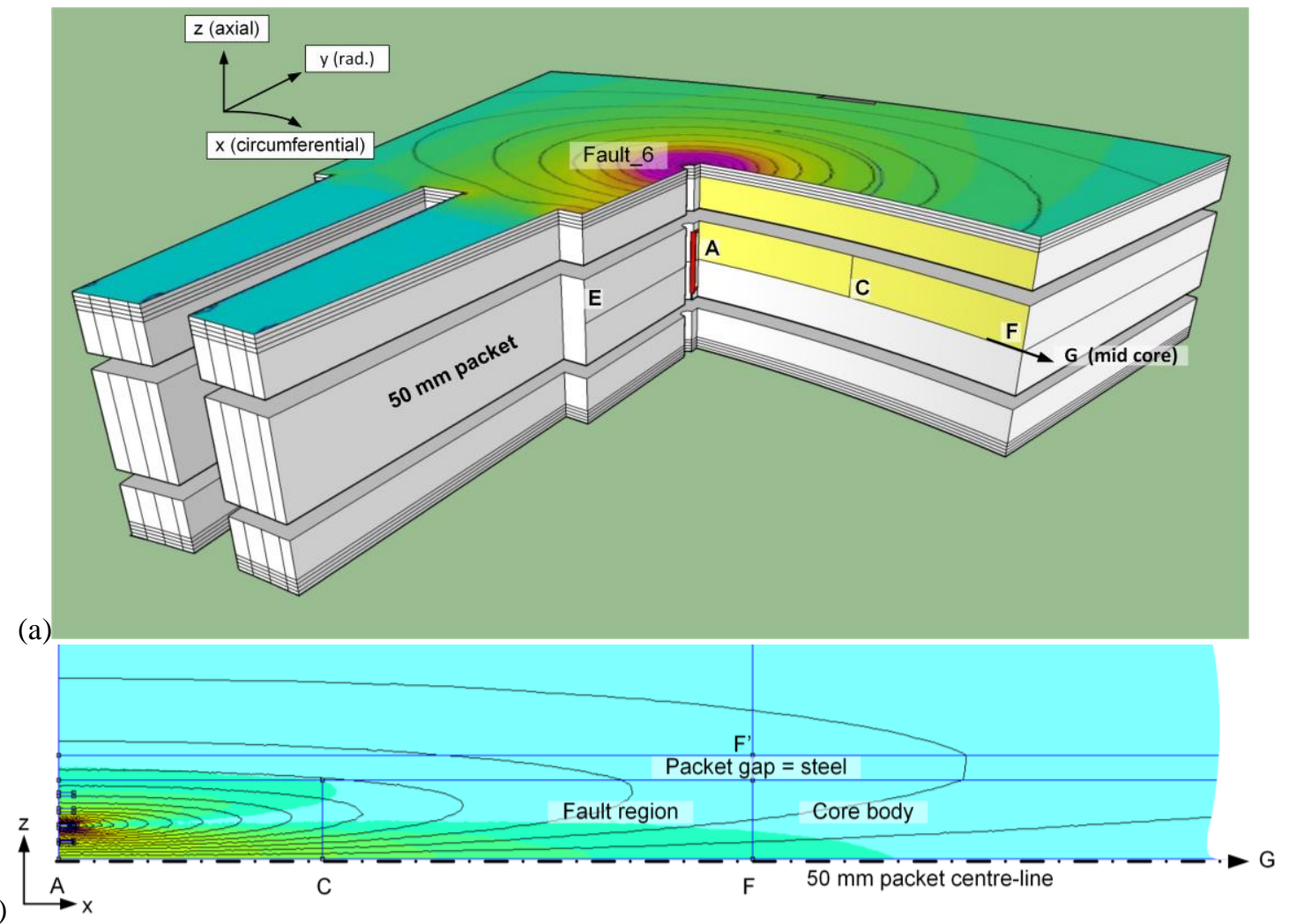

Figure 6. (a) Core body transverse model section, (b) 2D FE model

In a $2 \mathrm{D}$ magnetic model there is no flux density in the un-modelled $3^{\text {rd }}$ dimension, in this case the radial y-axis, which is essentially true for the great majority of the core body region. The difference in $\mathrm{x}$-axis core body section FG reluctance due to difference in flux divergence with/without packet air gaps was determined from the 2D FE transverse model. The permeability of the core body section of the axial model in Figure 5 was then changed to match these two reluctance values, allowing the differential effect of the core body packet air gaps on the detected fault signals to be computed in Table 3. 


\subsection{Fault Region Transverse 2D FE Model of Fault MPD}

To determine the impact of axial divergence of fault flux due to packet air gaps on the development of the fault mpd across the tooth roots, the fault region was modelled in a transverse 2D FE semi-circular axial section centred on the fault current. This cuts the $50 \mathrm{~mm}$ core packet along the locus BCDE with its end E on the slot base midline, with axial and circumferential mirror symmetry, and is coloured yellow in a sectioned view in Figure 7. As discussed above the locus BCDE also essentially follows the flux flow lines, approximating the 2D model assumption of zero flux normal to the model plane.

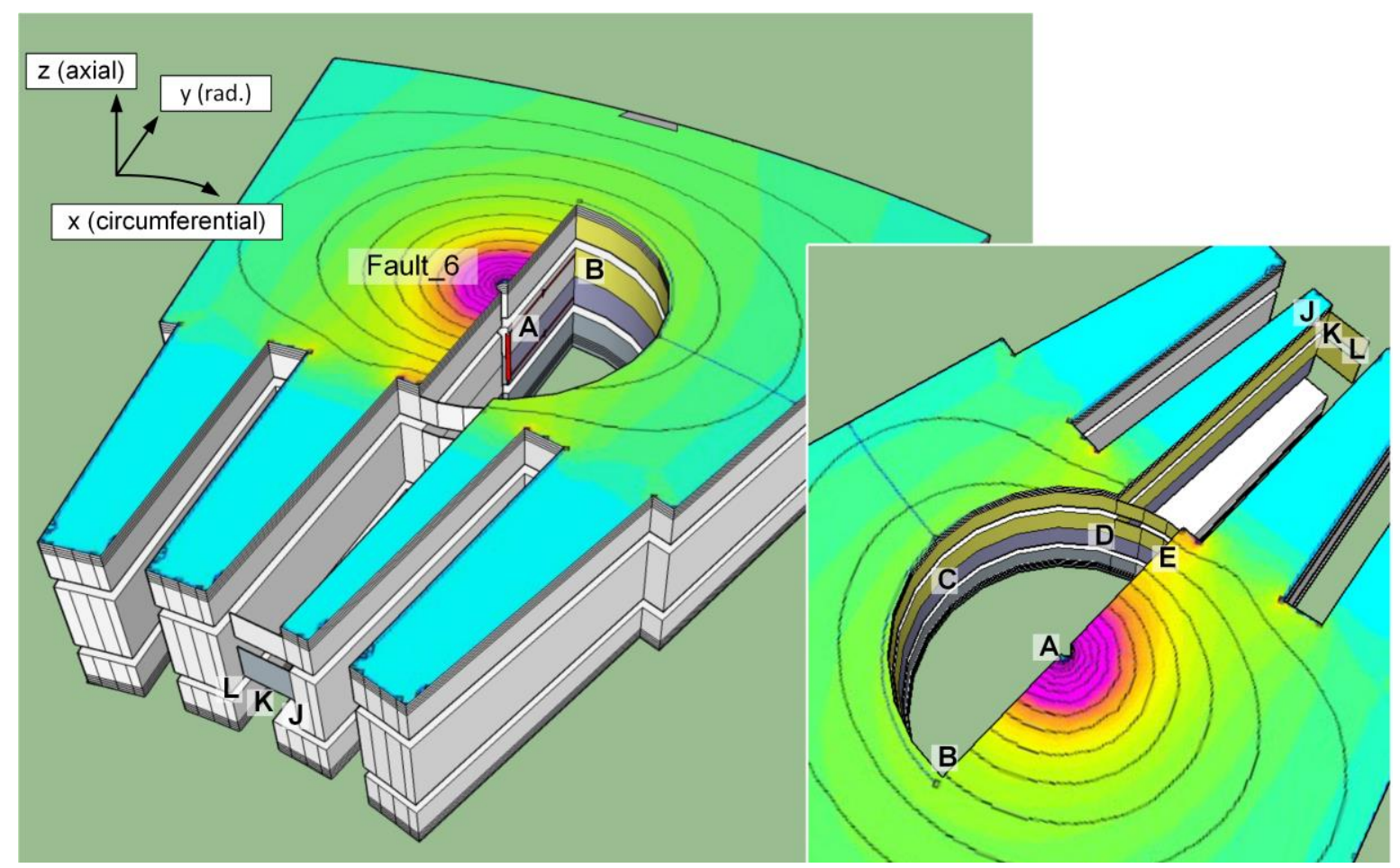

Figure 7. Fault and tooth region transverse model loci visualisations (inset rotated view for clarity)

The axial mpd profile developed across the tooth centre-line to slot centre on section locus DE, being the mpd presented to the teeth roots across DE for the $1 \mathrm{~A}$ fault current, was computed both with and without the presence of packet air gaps for the three fault lengths. However the presence/absence of packet air gaps causes a change in both the average and profile of the presented mpd, preventing generation of a single metric for the differential effect. Consequently the outputs from this model were presented to the tooth region to determine the combined change.

\subsection{Transverse Tooth 2D FE Model of Axial Flux Dispersion}

In order to determine the impact on the mpd detected by the Chattock across the tooth tips, the six mpd profiles generated by the above fault region transverse model across DE were presented to a third model of the tooth structure from slot base radially to the tooth tip. This is similarly affected by the presence or absence of the packet air gap. The necessary transverse tooth model is developed along the 
locus DJKL. Since the input reluctance of the model is very high due to the reluctance of the slot's air in locus KL, it will not 'load' the magnetic field from source DE significantly. To accommodate the flux leakage across the slot, the effective reluctance of the whole slot was simulated in the relative permeability at the $13 \mathrm{~mm}$ width end section KL.

FEMM uses an A-V electromagnetic model, thus a mmf field cannot be imposed. To resolve this, the input reluctance of the tooth models were computed step-wise along locus DNP and A (magnetic vector) Dirichlet boundary values imposed along DNP to achieve the flux density profile that generates the desired input mmf field.
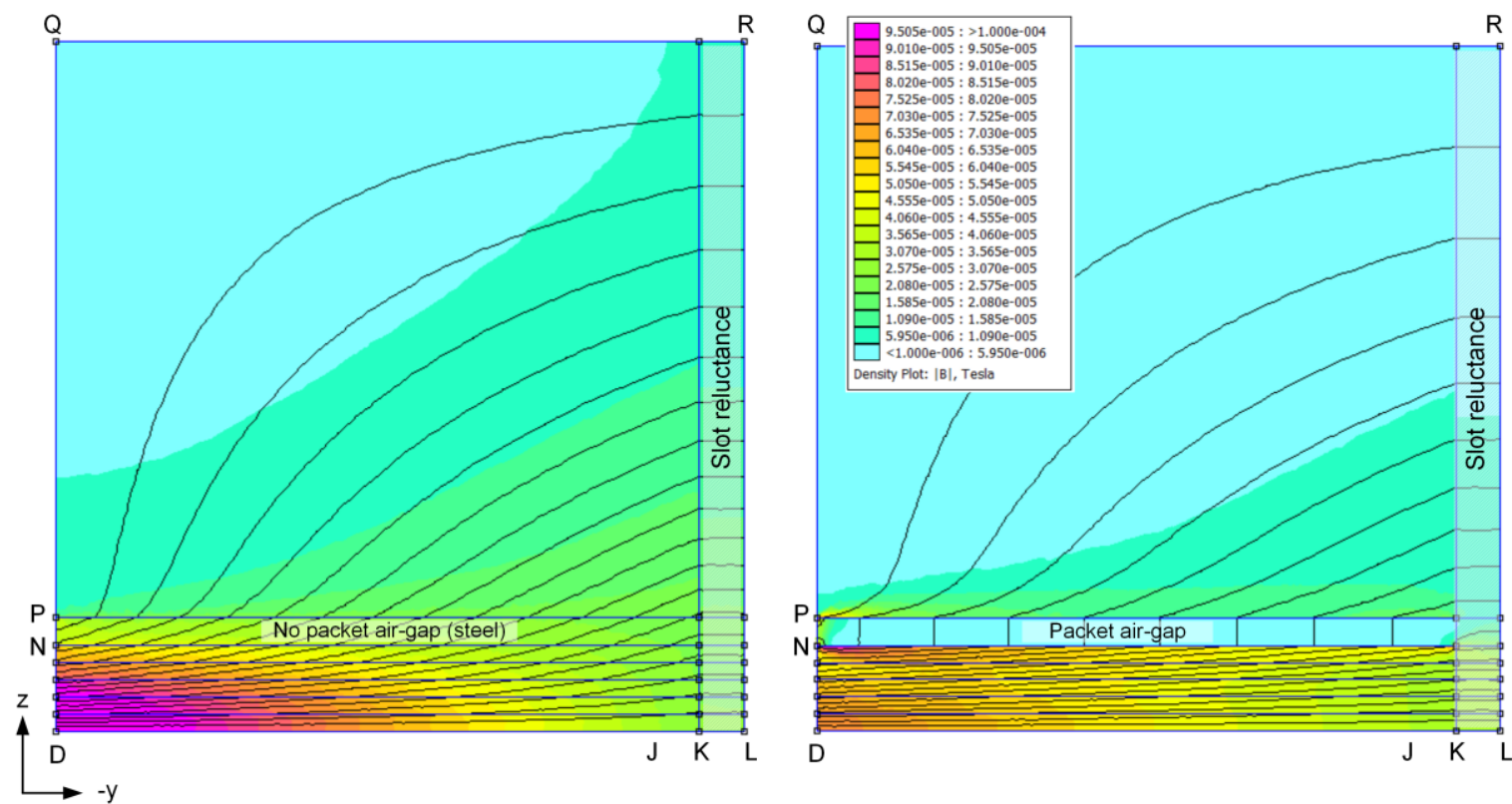

Figure 8. (a) 20 mm Fault_6 tooth transverse 2D FE model without packet air gaps, (b) with packet air gaps

The flux lines in Figure 8(a) show that in the absence of a constraining packet air gap, the flux and hence magnetic field strength developed by the fault at the tooth root spreads very substantially axially down the tooth. However the packet air gap in Figure 8(b) more substantially constrains the flux within the packet, increasing the magnetic field strength at the tooth tip. The y-axis mpd along the slot end KL was averaged $4 \mathrm{~mm}$ axially (z-axis) to simulate the spatial averaging of an EL CID Chattock for the six models. This allowed the final tooth tip mpd increase due to packet air gaps to be computed for the combined fault region and tooth models.

\subsection{Application of Transverse 2D FE models to $3 D$ FE model}

The cumulative increases in the 3D FE Quad simulated fault signals due to the packet air gaps, predicted by the combined 2D FE transverse models, is given in Table 3. These correction factors were 
applied to the Fault_6 3D FE model values and compared again to the measured DAX8 results scaled to the 3D FE geometry and equal fault current in Figure 9.

\begin{tabular}{l|r|r|r}
\hline Fault_6 length (mm) & \multicolumn{4}{|c}{ Quad signal increase due to air packet gaps } \\
\hline & Core body & Fault region and teeth & \multicolumn{2}{c}{ Total } \\
\hline 10 & $8.3 \%$ & $16.6 \%$ & $26.3 \%$ \\
\hline 20 & $9.5 \%$ & $18.8 \%$ & $30.0 \%$ \\
\hline 40 & $10.7 \%$ & $26.6 \%$ & $40.1 \%$ \\
\hline
\end{tabular}

Table 3. Packet air gap correction factors from $2 \mathrm{D}$ FE transverse models
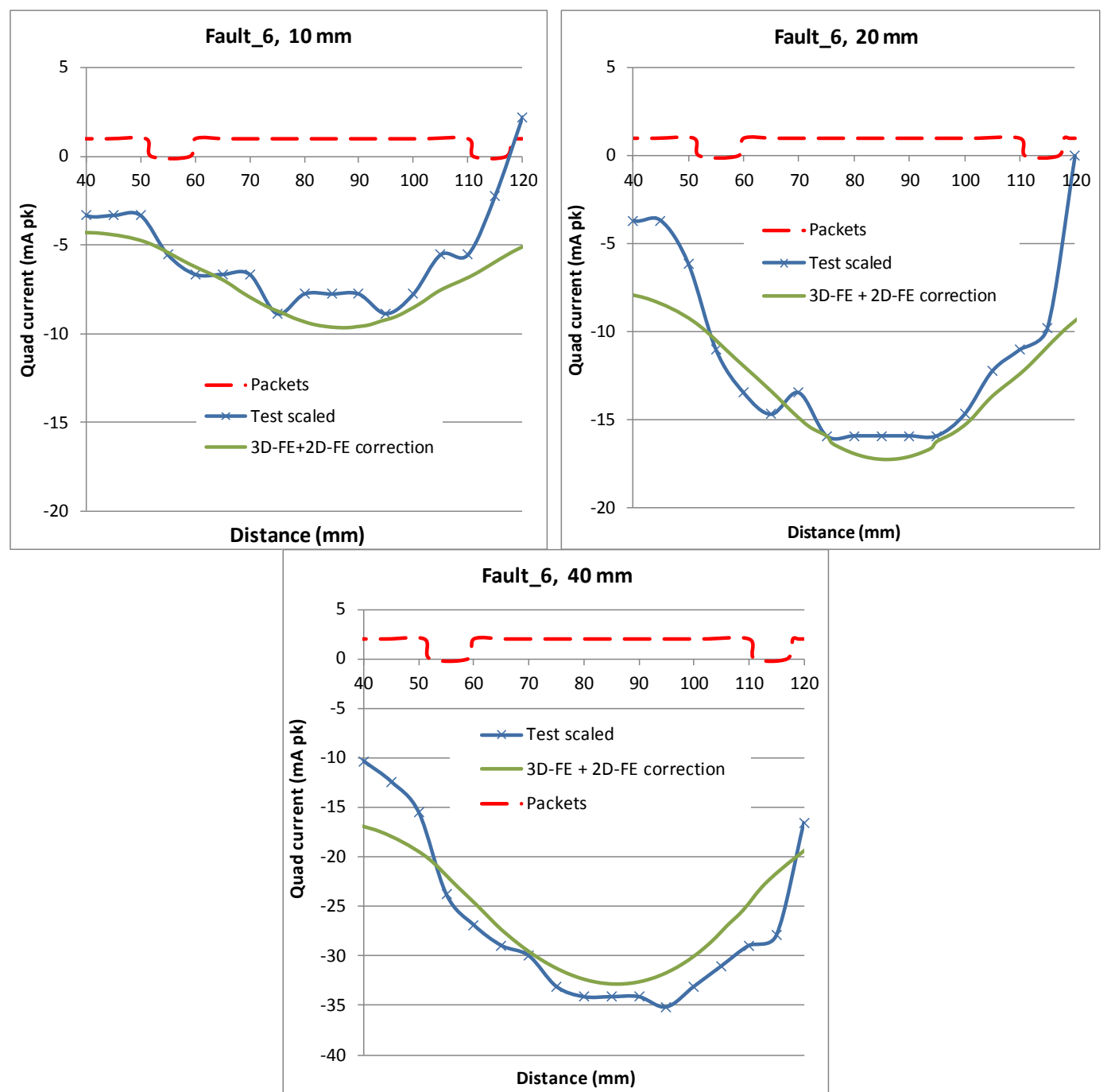

Figure 9. Air gap corrected 3D FE model results compared to tests at equal current

In these graphs it is clear, by the comparison with Figure 3, that adjusting for the effect of packet air gaps has resulted in a close match between 3D FE model and experiment. While the 2D FE transverse models only explicitly considered Fault_6, Fault_4 has similar depth, and will thus be similarly affected. Fault_5 will also be similarly affected by the tooth's flux divergence, but an unknown amount from the rest of the core. Subject to further study, the same correction as Fault_6 was applied to Fault_5. The 3D model prediction errors were averaged over each fault's length in Table 4. 


\begin{tabular}{l|c|r|r|r}
\hline & $\begin{array}{c}\text { Length } \\
\text { (mm) }\end{array}$ & $\begin{array}{c}\text { 3D FE error at } \\
\text { equal flux }\end{array}$ & $\begin{array}{c}\text { 3D FE error at } \\
\text { equal current }\end{array}$ & $\begin{array}{c}\text { 3D FE + air gap correction } \\
\text { error at equal current }\end{array}$ \\
\hline \multirow{2}{*}{ Fault_4 } & 10 & $20 \%$ & $-10 \%$ & $14 \%$ \\
\cline { 2 - 5 } & 20 & $13 \%$ & $-32 \%$ & $-11 \%$ \\
\cline { 2 - 5 } & 40 & $-28 \%$ & $-41 \%$ & $-17 \%$ \\
\hline \multirow{3}{*}{ Fault_5 } & 10 & $66 \%$ & $-25 \%$ & $-5 \%$ \\
\cline { 2 - 5 } & 20 & $-2 \%$ & $-34 \%$ & $-14 \%$ \\
\cline { 2 - 5 } & 40 & $-26 \%$ & $-34 \%$ & $-7 \%$ \\
\hline \multirow{3}{*}{ Fault_6 } & 10 & $6 \%$ & $-16 \%$ & $6 \%$ \\
\cline { 2 - 5 } & 20 & $13 \%$ & $-18 \%$ & $-7 \%$ \\
\hline \multirow{2}{*}{ Mean error } & 40 & $-22 \%$ & $-33 \%$ & $-3.8 \%$ \\
\hline Std. Dev. & & $4.5 \%$ & $-26.9 \%$ & $9.8 \%$ \\
\hline
\end{tabular}

Table 4. Analysis of error of $3 D$ FE prediction of buried fault test results.

The mean error provides an indication of the overall success of the 3D FE model in predicting a variety of buried fault test results. The standard deviation shows the uncertainty in those predictions. The results are plotted in Figure 10 to show the error distribution scatter.

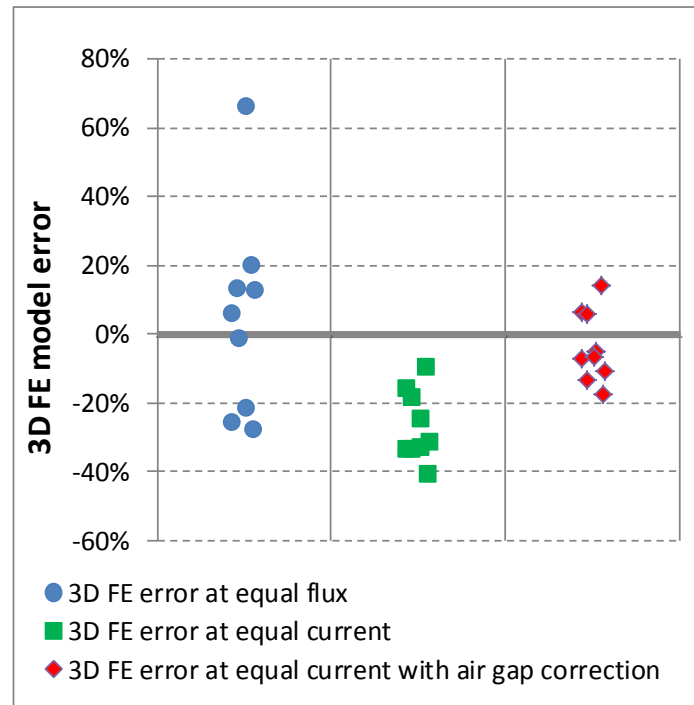

Figure 10. 3D FE model error distributions

\section{Detection Sensitivity to Fault Currents}

Knowledge of the mean fault currents also allows measurement of the EL CID detection sensitivity of faults on the stator core, expressed as the proportion of the fault current detected as the Quad signal, both by the 3D FE model (corrected for packet air gaps) and as measured. The 3D FE modelled surface faults, Fault_1-3, were adjusted to similarly reflect the mean of the modelled current over $90 \%$ of the fault length, with experimental measurements taken from [29]. The combined results for all six faults are shown in Table 5 and plotted in Figure 11. 


\begin{tabular}{|c|c|c|c|c|c|c|c|c|}
\hline \multirow{2}{*}{$\begin{array}{l}\text { Length/ } \\
\text { Fault }\end{array}$} & \multicolumn{2}{|c|}{$10 \mathrm{~mm}$} & \multicolumn{2}{|c|}{$20 \mathrm{~mm}$} & \multicolumn{2}{|c|}{$40 \mathrm{~mm}$} & \multicolumn{2}{|c|}{$60 \mathrm{~mm}$} \\
\hline & Model & Measured & Model & Measured & Model & Measured & Model & Measured \\
\hline Fault_1 & 0.350 & 0.288 & 0.505 & 0.472 & 0.617 & 0.646 & 0.690 & 0.747 \\
\hline Fault_2 & 0.265 & 0.250 & 0.418 & 0.449 & 0.607 & 0.650 & 0.704 & 0.767 \\
\hline Fault_3 & 0.167 & 0.157 & 0.283 & 0.320 & 0.469 & 0.537 & 0.600 & 0.767 \\
\hline Fault_4 & 0.017 & 0.015 & 0.024 & 0.027 & 0.046 & 0.055 & & \\
\hline Fault_5 & 0.063 & 0.067 & 0.122 & 0.142 & 0.244 & 0.263 & & \\
\hline Fault_6 & 0.020 & 0.019 & 0.036 & 0.033 & 0.068 & 0.072 & & \\
\hline
\end{tabular}

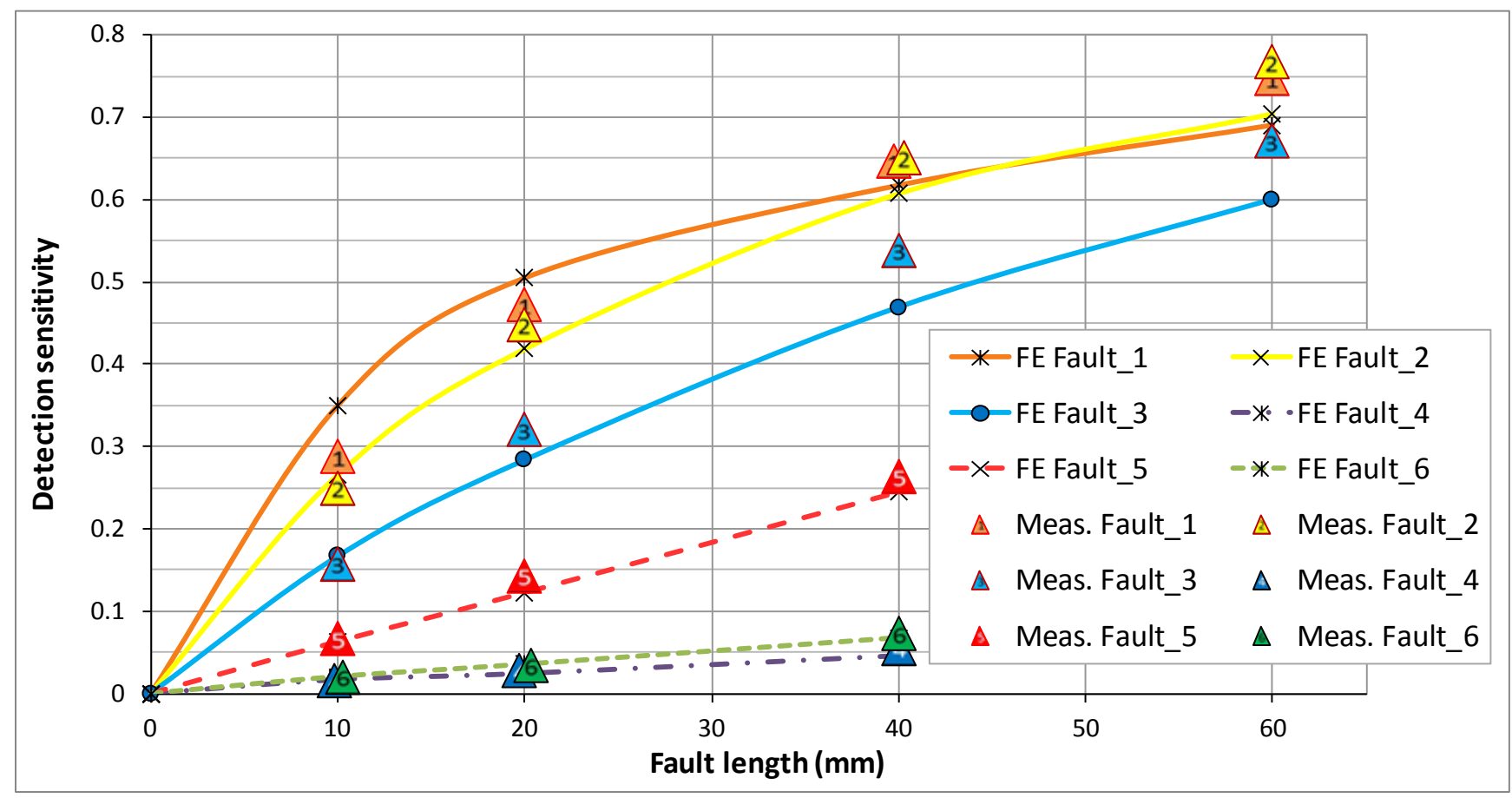

Figure 11. 3D FE modelled and measured Quad fault current detection sensitivities

\section{Discussion}

The errors in the 3D FE model of the fault current likely came from the use of a much larger fault diameter region with adjusted resistivity to solve FE meshing problems, reducing the impact of lamination resistivity. Correcting for this exposed the amplifying effect of the packet air gaps, for which the 2D FE air gap correction factors finally achieved a close mean prediction with only $-3.8 \%$ error and little variance.

A limitation with the 2D FE models is that any flux flowing axially between laminations will in practice also be resisted by eddy currents developed in the laminations, and be further affected by lamination joints. However these cannot yet be realistically modelled in 3D for reasons given earlier, thus this effect had to be ignored.

In section 4 it was shown that the slightly larger Test core may have a $-5.4 \%$ general error. This was not statistically reliable, but indicates that the mean combined 3D FE model error for buried faults 
This article has been accepted for publication in a future issue of this journal, but has not been fully edited.

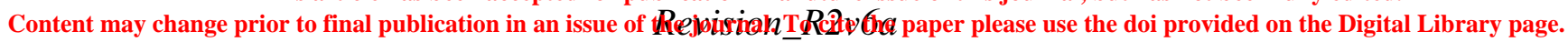

may be nearer to $-9 \%$, depending on the degree of covariance. This remains a good match considering the overall FE modelling complexity, and is less than the $10 \%$ error considered acceptable for stator core condition monitoring [34].

Low detection sensitivity to buried faults would appear to lead to acceptance of potentially damaging local temperatures, since the nominal $100 \mathrm{~mA} / 10^{\circ} \mathrm{C}$ correlation is for surface faults of $\sim 15 \mathrm{~mm}$ length with a 0.31 Chattock sensitivity. This implies that, at the $100 \mathrm{~mA}$ warning threshold, the buried tooth Fault_5 would reach $\sim 30{ }^{\circ} \mathrm{C}$ and the buried core yoke faults $\sim 100{ }^{\circ} \mathrm{C}$ for the same length fault. However the substantial thermal resistance of the surrounding steel will considerably attenuate this higher source temperature before reaching the thermally sensitive winding insulation. Conversely it does indicate that modest Quad signals from buried faults need to be considered very seriously, since $>300 \mathrm{~mA}$ may indicate fault temperatures in the yoke reaching the pyrolysis threshold of the interlamination insulation, and thus able to initiate a runaway core fault.

\section{Conclusion}

Buried faults in stator cores are difficult to detect by electromagnetic means since the fault's surrounding steel causes the surface mpd to be considerably attenuated, and are also difficult to adequately model or experimentally verify. Typical short fault lengths result in 2D FE models failing to represent the axial field generated, while full 3D FE models become computationally impractical when attempting to represent large laminated structures.

A sectional 3D FE core model using a homogenised lamination approximation had been constructed of stator core faults buried in the teeth and yoke, for which the results are newly presented. To validate these results, a new experimental methodology with corrections for electromagnetic intrusion was developed to apply calibrated buried faults non-destructively. This showed a variance between model and results due to imperfect modelling of fault-lamination resistivity and thus fault current, which was corrected by fault current measurement and compensation of results.

A further problem was the inability of the sectional 3D FE model to fully reflect the impact of images and normal packet air gaps in the whole core. Fault images caused by the necessity of a sectional model were quantified and corrections computed. Packet air gaps can increase the signal mpd due to axial constraint of fault flux, particularly on longer faults approaching the packet length. This was resolved by a series of transverse section 2D FE models to estimate the differential impact of this issue on the original modelled fault signals. Adjustment of the 3D FE model results for images and air gaps using the 2D FE models produced a close mean prediction error of just $-3.7 \%$ with low variance. 
From the results, electromagnetic test detection sensitivities to buried fault currents were reliably determined for the first time. These completed the set of comparative detection sensitivity measures for varying fault lengths, quantifying the threat that a detected buried stator core fault may present.

\section{Acknowledgments}

The authors wish to acknowledge the support provided by ENELEC LTD, Iris Power LP, the Knowledge Transfer Partnership Scheme UK, Brush Electrical Machines Ltd and Areva T\&D.

\section{References}

1. "Repair and testing guide for generator laminated cores grounded at the core outside diameter". EPRI; Palo Alto, USA, Report No.: 1007441, 2002; pp. 89.

2. Stone G. C., Culbert I., Boulter E. A., Dhirani H. "Electrical insulation for rotating machines: design, evaluation, aging, testing and repair". 2 ed. Wiley, 2014.

3. Tavner P. J., Anderson A. F. "Core faults in large generators". IEE Proceedings, Electrical Power Applications. November; Vol.:152(6), 2005, pp. 1427-39.

4. Tavner P., Ran L., Penman J., Sedding H. "Condition monitoring of rotating electrical machines". 2 ed. Institution of Engineering Technology, 2008.

5. 'Guide for diagnostic field testing of electric power apparatus'. vol. IEEE Std 62.2-2004 USA: IEEE, pp. 1-100, (2005).

6. Sutton J.; Central Electricity Generating Board, assignee. "Method of and apparatus for testing laminated magnetic cores". UK patent GB 2044936A, 1979.

7. "EL CID (Electromagnetic - Core Imperfection Detector) testing of large steam-turbine-driven generators". CIGRE; Paris, Report No.: TB 257, 2004; pp. 12.

8. Bertenshaw D. R. "Analysis of stator core faults - a fresh look at the EL CID vector diagram". Hydro 2006; September; Porto Carras, Greece. The International Journal on Hydropower \& Dams; 2006. pp. 15.02, 1-10.

9. $\quad$ "EL CID Evolution User Manual". V6 ed. Qualitrol - Iris Power; Toronto, Canada, 2014.

10. Bertenshaw D. R., Smith A. C. "Field correlation between electromagnetic and high flux stator core tests". PEMD 2012, The 6th IET International Conference on Power Electronics, Machines and Drives; March; Bristol, UK. IET; 2012. pp. 0025/1-6.

11. Bertenshaw D. R., Smith A. C. "Studies into the effectiveness of the electromagnetic stator core test". CIGRE Science \& Engineering Journal. February; Vol.:4, 2016, pp. 37-52.

12. Edmonds J. S., Daneshpooy A., Murray S. J., Sire R. A. "Turbogenerator stator core study". SDEMPED 2007, IEEE International Symposium on Diagnostics for Electric Machines, Power Electronics and Drives; September; Cracow, Poland. IEEE; 2007. pp. 441-6.

13. "Guide on economic evaluation of refurbishment / replacement decisions on generators". CIGRE; Paris, Report No.: TB641, 2015; pp. 74.

14. Bertenshaw D. R., Chan T., Smith A. C., Ho C. W. "Computational modelling of stator core faults in large hydrogenerators and turbogenerators". Hydro 2004; October; Porto, Portugal. . The International Journal on Hydropower \& Dams; 2004. pp. 17.4, 1-8.

15. Gandshu V. M., Gorodov V. V., Dubitsky S., Podnos V. "Theoretical analysis of the ELCID method using QuickField FEA package". ICEM2006 XVIIth International Conference on Electrical Machines; 2-5 September; Chania, Crete. 2006. pp. OTA3-5.

16. Makuc D., Berlec M., Lenasi K. "Investigation of ELCID testing using FEM analysis and test core measurements". Studies in Applied Electromagnetics and Mechanics, Electromagnetic Fields in 
Mechatronics, Electrical and Electronic Engineering - Proceedings of ISEF'05; August. 2006. pp. 199204.

17. Bertenshaw D. R., Smith A. C., Ho C. W., Chan T., Sasic M. "Detection of stator core faults in large electrical machines". IET Electric Power Applications. July; Vol.:6(6), 2012, pp. 295-301.

18. Müller J. L., Benabou A., Henneron T., Piriou F., Bastos J. P. A., Roger J.-Y. "Study of different FEM models to analyze homogenized iron lamination with electrical fault". COMPUMAG 2009; November; Florianopolis, Brazil. 2009. pp. 739-40.

19. Müller J. L., Benabou A., Henneron T., Piriou F., Bastos J. P. A., Roger J.-Y. "3D FE modelling of interlamination short-circuits taking into account the building bars". COMPUMAG 2011; July; Sydney. 2011. pp. 1084-5.

20. Müller J. L., Romary R., Benabou A., Henneron T., Piriou F., Bastos J. P. A., Roger J.-Y. "Interlaminar short circuit detection: modeling and measurement". COMPEL. September; Vol::31(5), 2012, pp. 1448 - 57.

21. Nakata T., Takahashi N., Fujiwara K., Shiraki Y., editors. "3-D Magnetic field analysis by using special elements". Digests of INTERMAG '90 International Magnetics Conference, 1990; 1990 17-20 April. pp. FD-07.

22. Nakano T., Kawase Y., Yamaguchi T., Nakamura M., Nishikawa N. "3-D Finite Element Analysis of Eddy Current in Laminated Cores of the Interior Permanent-Magnet Motor". IEEE Transactions on Magnetics. Vol.:49(5), 2013, pp. 1945-8.

23. Rettler R., Brauer J. "Computer simulation of inter-laminar insulation failure and EL CID testing". Joint CIGRE and EPRI Rotating Machine Colloquium; Florida USA. EPRI; 1999. pp. 21.

24. Smith A. C., Bertenshaw D. R., Ho C. W., Chan T., Sasic M. "Detection of stator core faults in large turbo-generators". IEMDC2009; 3-6 May; Miami, USA. IEEE; 2009. pp. 911-8.

25. Sutton J. "Theory of electromagnetic testing of laminated stator cores". Insight - Journal of the British Institute of Non-Destructive Testing. April Vol.:36(4), 1994, pp. 246-51.

26. Henneron T., Piriou F., Roger J.-Y. "An approach to determine the circulation of magnetic field in FEM computation code with vector potential formulation". IEEE Transactions on Magnetics. May Vol.:47(5), 2011, pp. 1354-7.

27. "Generator core overheating risk assessment - core model studies". EPRI, USA., Report No.: 1009855, 2004; pp. 152.

28. Paley D. B., McNamara B., Mottershead G., Onken S. C. "Verification of the effectiveness of EL CID on a hydrogenerator stator core". Hydrovision '98; June; USA. ADWEL International Ltd Technical Publication 06/98; 1998. pp. 1-14.

29. Ho C. W., Bertenshaw D. R., Smith A. C., Chan T., Sasic M. "Three-dimensional finite element analysis of large electrical machine stator core faults". Electric Power Applications, IET. Vol.:8(2), 2014, pp. 60-7.

30. Bertenshaw D. R., Chapman B. "EL CID results interpretation in the presence of substantial core faults". EPRI European Turbine Generator User Group Workshop; June Madrid, Spain. EPRI; 2009. pp. 6.

31. Bertenshaw D. R., Smith A. C. "The impact of non-linear permeability on electromagnetic stator core tests". PEMD 2014, The 7th IET International Conference on Power Electronics, Machines and Drives; 8-10 April; Manchester, UK. IET; 2014. pp. 0052/1-6.

32. Meeker D. C., 'FEMM: Finite Element Method Magnetics', 4.2 ed: http://www.femm.info, (2013).

33. Reece A. B. J., Preston T. W. "Finite element methods in electrical power engineering". Oxford University Press, 2000.

34. Ridley K. "Evaluation of interlamination circulating current at core joints in large machine stators". Hydro 2010; 27-29 September; Lisbon. 2010. pp. 1-9.

Total word count $=5958$, Less Affiliations, Tables, Captions and this text $=538$ words, Nett word count $=5420$ 